\title{
Asymptomatic neurocognitive disorders in patients infected by HIV: fact or fiction?
}

\author{
Carlo Torti $^{{ }^{*}}$, Emanuele Focà ${ }^{1}$, Bruno M Cesana ${ }^{2}$ and Francois X Lescure ${ }^{3}$
}

\begin{abstract}
Neurocognitive disorders are emerging as a possible complication in patients infected with HIV. Even if asymptomatic, neurocognitive abnormalities are frequently detected using a battery of tests. This supported the creation of asymptomatic neurocognitive impairment (ANI) as a new entity. In a recent article published in BMC Infectious Diseases, Magnus Gisslén and colleagues applied a statistical approach, concluding that there is an overestimation of the actual problem. In fact, about $20 \%$ of patients are classified as neurocognitively impaired without a clear impact on daily activities. In the present commentary, we discuss the clinical implications of their findings. Although a cautious approach would indicate a stricter follow-up of patients affected by this disorder, it is premature to consider it as a proper disease. Based on a review of the data in the current literature we conclude that it is urgent to conduct more studies to estimate the overall risk of progression of the asymptomatic neurocognitive impairment. Moreover, it is important to understand whether new biomarkers or neuroimaging tools can help to identify better the most at risk population. Please see related article: http://www.biomedcentral. com/1471-2334/11/356
\end{abstract}

Keywords: HIV, asymptomatic neurocognitive impairment, HIV dementia, HAART

\section{Introduction}

As HIV-infected patients are living longer thanks to highly active antiretroviral therapy (HAART), our objective as clinicians is to offer them a life expectancy and a quality of life comparable to individuals not infected by

\footnotetext{
* Correspondence: torti@med.unibs.it

'Institute for Infectious and Tropical Diseases, University of Brescia, P.le Spedali Civili, 125123 Brescia, Italy

Full list of author information is available at the end of the article
}

HIV. Unfortunately, several complications are emerging as a consequence of premature aging, an effect of persistent or non-reversible immune-activation and concomitant risk factors (such as smoking or use of recreational drugs) or co-infections (such as chronic hepatitis C) [1]. HIV-associated neurocognitive disorders (HAND) could be one of the most important complications, the accepted prevalence of HAND today is approximately $50 \%$ despite the overall efficacy of HAART [2]. Indeed, several patients are being diagnosed with a broad spectrum of neurocognitive impairments ranging from subtle alterations that are only evident through specific tests (that is, asymptomatic neurocognitive impairment (ANI)) to mild neurocognitive disorders (MND) that start having deleterious effects on patients' daily activities [3]. Moreover, despite the fact that HIV-associated dementia (HAD) is currently controlled [4], there is a concern that neurocognitive disorders will worsen even on HAART, leading to a resurgence of this problem in the future. This concern is based on patients on HAART who have neurological deficits despite persistent undetectable HIV RNA in plasma [5], but with detectable HIV RNA in the cerebrospinal fluid (CSF) [6], neuroinflammation in the CSF [7], or $ß$-amyloid deposition in the brain [8].

The American Academy of Neurology (AAN) updated the nosology of HAND in 2007, introducing ANI as a new pathological entity [9]. The panel itself recommended using this classification only for research. Indeed, this entity had been evaluated in only two studies concerning a small number of ANI-suffering patients before consensual but not unanimous approval $[10,11]$. Notwithstanding this consideration, it has already been adopted into clinical practice. For instance, the Italian guidelines for HIV disease management suggest starting HAART in all patients with HAND, a recommendation that is stronger for those with MND but also applies to those with ANI [12].

In the accompanying paper published in $B M C$ Infectious Diseases, Gisslèn et al. [13] emphasize that a high proportion of HIV infected patients (about 20\%) may be

\section{Ciomed Central}


classified as neurocognitively abnormal (though asymptomatic) using the AAN criteria. According to this classification, ANI is characterized by neuropsychological testing outcomes that are at least one standard deviation below the mean of normative scores in at least two cognitive areas among at least five domains. The authors highlighted that, according to this criterion, even in a general population with a normal distribution of the neuropsychological testing outcomes, almost $16 \%$ of the individuals will be defined as abnormal. The bottom line is that the definition of ANI may lead to an unacceptable false-positive rate and that therefore the actual problem is overestimated.

\section{Discussion}

\section{Statistical considerations}

From a statistical point of view, in addition to the results of the paper by Gisslèn et al. [13], it is interesting to note that in the case of independent tests exhibiting a Gaussian distribution the probability of having all scores of the five tests more than one standard deviation from their mean is only about 0.42 (as demonstrated both by the probability of only one test being abnormal, which is 0.84134 , raised to five and by simulations that we have performed); so, the probability of having something not 'absolutely normal', according to the AAN proposed threshold (one standard deviation lower than the mean), is less favorable than tossing a coin. Of course, the very high probability value of making a diagnosis of ANI together with the above result immediately emphasizes the problem of the false positive proportion and, consequently, the need for a critical consideration of the validity of diagnostic criteria based on the 'z-score'. Indeed, it is common to obtain some z-score values associated with a low probability value, meaning that it is practically impossible from a Gaussian distribution [14]. Moreover, the Gaussian model could be limited since it may include impossible negative values; this happens, for instance, for values lower than two standard deviations less than the mean of the raw values (that is, the neuropsychological test results without adjusting for the normative values). According to these considerations, it would be more advisable not to rely upon some asymptotic results from the statistical theory (central limit theorem) leading to the Gaussian model, but to refer to skewed distributions and to calculate non-parametric thresholds ( 0.95 quantile, for example, or its lower 95\% confidence limit). We actually think that, when an immediate medical treatment is not required as in the case of an ANI, knowing that a patient is under some relevant quantiles $(0.5,0.10$ or 0.25$)$ of the 'reference population' can be more informative for monitoring his/her follow-up than a result based on a parametric model (one standard deviation less than the mean), which may be too restrictive and not able to fit well with a set of real observations.

\section{Clinical considerations}

From a clinical point of view, it is important to highlight that, being asymptomatic, ANI is not an overt disease, so it would be clinically relevant only if it had been correlated with signs of definite pathologies or if it had been shown to be predictive of more severe neurocognitive impairments. Although a cross-sectional study demonstrated a correlation between pathological evidence of HIV encephalitis at autopsy and ANI diagnosed ante-mortem, this study is limited because it involved only the most compromised patients who died, so results are not transferable to the general population [11]. Moreover, it is a little disconcerting to find that, using the AAN criteria, even $16 \%$ to $19 \%$ HIV-negative young people about 35 years old who were used as controls had neurocognitive disorders in the study by Heaton et al. [3]. Lastly, in the five years after ANI was defined [9], no single study was performed to assess its predictive value for MND or HAD. Therefore, it remains plausible that patients with ANI have a greater risk of progression to MND/HAD than those without, but this is currently uncertain and may be difficult to demonstrate for several reasons:

(i) since neurocognitive impairment has been correlated with a variety of conditions (such as psychiatric disorders or psychoactive medications, recreational drugs, alcohol abuse, chronic hepatitis $\mathrm{C}$, metabolic abnormalities, vascular disease, and even potential neurotoxicity of antiretroviral drugs) [15-22], it is difficult to properly select the cases where the effect of HIV is predominant, which are more probably destined to MND and HAD;

(ii) HAART is likely to improve the evolution of HIV-associated neurocognitive impairment [23], so studies on the natural history of this disease are difficult to conduct;

(iii) neurocognitive impairment may fluctuate over time [24], implying that the disease may spontaneously recover or that the prodromic stages of dementia (ANI and MND) are not strongly predictive. This has been already proven for mild cognitive impairment in aging-associated cognitive decline [25];

(iv) the pathogenesis of neurocognitive disorders involves multiple signs [26], whose relationships are for the most part not elucidated. It is possible that neurocognitive disorders comprise heterogeneous conditions whose prognosis and treatment are different. So the question is: can new biomarkers and/or neuroimaging techniques help disentangle the different nosological entities?

Several studies have investigated biomarkers and found that signs of persistent immune-activation in the 
CSF (such as pleocytosis, increased albumin concentration, neopterin, neurofilaments, IL-6, cholesterol, myoinositol) [7,27-30] or chronic peripheral activation (indicated by CD14, CD16 or lipopolysaccharide) [31-33] correlated with neurological impairment. As for neuroimaging, recently developed tools are promising. For instance, magnetic resonance spectroscopy is able to show a decreased level of $\mathrm{N}$-acetyl aspartate, a sign of mature neurons and their axonal processes, in the basal ganglia of patients infected by HIV; moreover, decreased levels of $\mathrm{N}$-acetyl aspartate were accompanied by increased choline and myoinositol as signs of cell turnover and inflammation [34]. Interestingly, these markers may be restored by HAART, and this may be correlated with improvement of neurocognition [35]. It has to be seen whether incorporation of these biomarkers or neuroimaging results into diagnostic algorithms may improve the clinical predictive value and relevance of subtle neurocognitive impairments such as ANI.

\section{Considerations for clinical management}

In the meantime, what should clinicians do when a diagnosis of ANI is made? Clearly, with the current diagnostic definition, ANI should not be assumed to be synonymous with an overt pathology or a major risk for HAD. Some experts recommend, as a cautious approach, to retest patients with ANI with the aim of identifying early on, any sign of progression of the neurocognitive disorder [12]. However, this practice should not excessively preoccupy our patients, leading to anxiety and depression for a condition that may not be significant. This is important in light of the fact that some patients, up to $53 \%$, suffer from ANI (as currently defined) [5].

\section{Conclusions}

In principle, the burden of ANI as a possible disease is huge in the HIV infected population. However, at present, this condition is more theoretical than real because it has not been validated for its relevance in clinical practice. Appropriately designed studies are urgently needed to understand whether this ANI is clinically meaningful or a false alarm both for patients and for physicians. In other words, a clinical validation of ANI is a priority before strong clinical recommendations are made. Since this condition may be heterogeneous, both in terms of pathogenesis and outcome, it has to be ascertained whether new biomarkers and neuroimaging techniques can help identify the most at risk patients. In the meantime, a cautious approach is recommended to monitor patients with ANI for progression of their neurological impairment, but this should be done without worrying our patients too much.

\begin{abstract}
Abbreviations
AAN: American Academy of Neurology; ANI: asymptomatic neurocognitive impairment; CSF: cerebrospinal fluid; HAART: highly active antiretroviral therapy; HAD: HIV-associated dementia; HAND: HIV-associated neurocognitive disorder; IL-6: interleukin-6; MND: mild neurocognitive disorder
\end{abstract}

\section{Author details}

'Institute for Infectious and Tropical Diseases, University of Brescia, P.le Spedali Civili, 125123 Brescia, Italy. ${ }^{2}$ Medical Statistics and Biometry Section, University of Brescia, Centro Didattico Polifunzionale, Viale Europa, 1125123 Brescia, Italy. ${ }^{3}$ Infectious and Tropical Diseases Department, APHP, Tenon Hospital, Paris 6 University, Rue de la Chine, 475020 Paris, France.

\section{Authors' contributions}

All authors conceived the concept and design of the commentary. CT, EF and FXL wrote the clinical part of the commentary. BMC wrote the statistical part of the commentary. All authors contributed to revision and approval of the final commentary for submission.

\section{Competing interests}

The authors declare that they have no competing interests.

Received: 21 December 2011 Accepted: 28 December 2011

Published: 28 December 2011

\section{References}

1. Deeks SG: HIV infection, inflammation, immunosenescence, and aging. Annu Rev Med 2011, 62:141-155.

2. Valcour V, Paul R, Chiao S, Wendelken LA, Miller B: Screening for cognitive impairment in human immunodeficiency virus. Clin Infect Dis 2011, 53:836-842.

3. Heaton RK, Clifford DB, Franklin DR Jr, Woods SP, Ake C, Vaida F, Ellis RJ, Letendre SL, Marcotte TD, Atkinson JH, Rivera-Mindt M, Vigil OR, Taylor MJ, Collier AC, Marra CM, Gelman BB, McArthur JC, Morgello S, Simpson DM, McCutchan JA, Abramson I, Gamst A, Fennema-Notestine C, Jernigan TL, Wong J, Grant I, CHARTER Group: HIV-associated neurocognitive disorders persist in the era of potent antiretroviral therapy: CHARTER Study. Neurology 2010, 75:2087-2096.

4. Lescure FX, Omland LH, Engsig FN, Roed C, Gerstoft J, Pialoux G, Kronborg G, Larsen CS, Obel N: Incidence and impact on mortality of severe neurocognitive disorders in persons with and without HIV infection: a Danish nationwide cohort study. Clin Infect Dis 2011, 52:235-243.

5. Simioni S, Cavassini M, Annoni JM, Rimbault Abraham A, Bourquin I, Schiffer V, Calmy A, Chave JP, Giacobini E, Hirschel B, Du Pasquier RA: Cognitive dysfunction in HIV patients despite long-standing suppression of viremia. AIDS 2010, 24:1243-1250.

6. Canestri A, Lescure FX, Jaureguiberry S, Moulignier A, Amiel C, Marcelin AG, Peytavin G, Tubiana R, Pialoux G, Katlama C: Discordance between cerebral spinal fluid and plasma HIV replication in patients with neurological symptoms who are receiving suppressive antiretroviral therapy. Clin Infect Dis 2010, 50:773-778.

7. Yilmaz A, Price RW, Spudich S, Fuchs D, Hagberg L, Gisslén M: Persistent intrathecal immune activation in HIV-1-infected individuals on antiretroviral therapy. J Acquir Immune Defic Syndr 2008, 47:168-173.

8. Clifford DB, Fagan AM, Holtzman DM, Morris JC, Teshome M, Shah AR Kauwe JS: CSF biomarkers of Alzheimer disease in HIV-associated neurologic disease. Neurology 2009, 73:1982-1987.

9. Antinori A, Arendt G, Becker JT, Brew BJ, Byrd DA, Cherner M, Clifford DB, Cinque P, Epstein LG, Goodkin K, Gisslen M, Grant I, Heaton RK, Joseph J, Marder K, Marra CM, McArthur JC, Nunn M, Price RW, Pulliam L, Robertson KR, Sacktor N, Valcour V, Wojna VE: Updated research nosology for HIV-associated neurocognitive disorders. Neurology 2007, 69:1789-1799.

10. Cherner M, Masliah E, Ellis RJ, Marcotte TD, Moore DJ, Grant I, Heaton RK: Neurocognitive dysfunction predicts postmortem findings of HIV encephalitis. Neurology 2002, 59:1563-1567.

11. Cherner M, Cysique L, Heaton RK, Marcotte TD, Ellis RJ, Masliah E, Grant I, HNRC Group: Neuropathologic confirmation of definitional criteria for 
human immunodeficiency virus-associated neurocognitive disorders. J Neurovirol 2007, 13:23-28.

12. Linee Guida Italiane sull'utilizzo dei farmaci antiretrovirali e sulla gestione diagnostico-clinica delle persone con infezione da HIV-1. Ottobre 2011 [http://www.salute.gov.t//imgs/ C_17_pubblicazioni_1301_allegato.pdf], Last accessed on December 14, 2011.

13. Gisslèn M, Price RW, Nilsson S: The definition of HIV-associated neurocognitive disorders: are we overestimating the real prevalence? BMC Inf Dis 2011, 11:356

14. Vita A, De Peri L, Barlati S, Cacciani P, Deste G, Poli R, Agrimi E, Cesana BM, Sacchetti E: Effectiveness of different modalities of cognitive remediation on symptomatological, neuropsychological, and functional outcome domains in schizophrenia: A prospective study in a real-world setting. Schizophr Res 2011, 133:223-231.

15. Castellon SA, Hinkin CH, Myers HF: Neuropsychiatric disturbance is associated with executive dysfunction in HIV-1 infection. J Int Neuropsychol Soc 2000, 6:336-347.

16. Bing $E G$, Burnam $M A$, Longshore $D$, Fleishman $J A$, Sherbourne $C D$, London AS, Turner BJ, Eggan F, Beckman R, Vitiello B, Morton SC, Orlando M, Bozzette SA, Ortiz-Barron L, Shapiro M: Psychiatric disorders and drug use among human immunodeficiency virus-infected adults in the United States. Ach Gen Psychiatry 2001, 58:721-728.

17. Zhang L, Looney D, Taub D, Chang SL, Way D, Witte MH, Graves MC, Fiala M: Cocaine opens the blood-brain barrier to HIV-1 invasion. J Neurovirol 1998, 4:619-626.

18. Meyerhoff DJ: Effects of alcohol and HIV infection on the central nervous system. Alcohol Res Health 2001, 25:288-298.

19. Parsons TD, Tucker KA, Hall CD, Robertson WT, Eron JJ, Fried MW, Robertson KR: Neurocognitive functioning and HAART in HIV and hepatitis C virus co-infection. AIDS 2006, 20:1591-1595.

20. Wright EJ, Grund B, Robertson K, Brew BJ, Roediger M, Bain MP, Drummond F, Vjecha MJ, Hoy J, Miller C, Penalva de Oliveira AC, Pumpradit W, Shlay JC, El-Sadr W, Price RW, INSIGHT SMART Study Group: Cardiovascular risk factors associated with lower baseline cognitive performance in HIV-positive persons. Neurology 2010, 75:864-873.

21. Ances BM, Sisti D, Vaida F, Liang CL, Leontiev O, Perthen JE, Buxton RB, Benson D, Smith DM, Little SJ, Richman DD, Moore DJ, Ellis RJ, HNRC group: Resting cerebral blood flow: a potential biomarker of the effect of HIV in the brain. Neurology 2009, 73:702-708.

22. Ciccarelli N, Fabbiani M, Di Giambenedetto S, Fanti I, Baldonero E, Bracciale L, Tamburrini E, Cauda R, De Luca A, Silveri MC: Efavirenz associated with cognitive disorders in otherwise asymptomatic HIVinfected patients. Neurology 2011, 76:1403-1409.

23. Cohen RA, Boland R, Paul R, Tashima KT, Schoenbaum EE, Celentano DD, Schuman P, Smith DK, Carpenter CC: Neurocognitive performance enhanced by highly active antiretroviral therapy in HIV-infected women. AIDS 2001, 15:341-345.

24. Robertson KR, Smurzynski M, Parsons TD, Wu K, Bosch RJ, Wu J, MCArthur JC, Collier AC, Evans SR, Ellis RJ: The prevalence and incidence of neurocognitive impairment in the HAART era. AIDS 2007, 21:1915-1921.

25. Ritchie $K$, Artero S, Touchon J: Classification criteria for mild cognitive impairment: a population-based validation study. Neurology 2001, 56:37-42.

26. Paul RH, Sacktor NC, Valcour V, Tashima KT: HIV and the Brain. New Challenges in the Modern Era. 1 edition. Humana Press; 2009.

27. Harezlak J, Buchthal S, Taylor M, Schifitto G, Zhong J, Daar E, Alger J, Singer E, Campbell T, Yiannoutsos C, Cohen R, Navia B, HIV Neuroimaging Consortium: Persistence of HIV-associated cognitive impairment, inflammation, and neuronal injury in era of highly active antiretroviral treatment. AIDS 2011, 25:625-633.

28. Letendre S, Croteau D, Ellis R, Clifford D, Gelman B, Marra C, McArthur J, McCutchan A, Simpson D, Grant I, CHARTER Group: Lower CSAR Are Associated with Global Neurocognitive Impairment in Antiretroviraltreated People with HIV. 18th Conference on Retroviruses and Opportunistic Infections, Boston MA 2011, Abstract 408

29. Anderson C, Sacktor N, McArthur J, Nath A: CSF Neurofilament H Levels in $\mathrm{HIV}^{+}$Individuals with Normal Cognition Predict Deterioration. 18th Conference on Retroviruses and Opportunistic Infections, Boston MA 2011, Abstract 407.
30. Schouten J, Cinque P, Gisslen M, Reiss P, Portegies P: HIV-1 infection and cognitive impairment in the CART era: a review. AIDS 2011, 25:561-575.

31. Carsenti-Dellamonica H, Vassallo M, Pradier C, Durant J, Harvey-Langton A, Lebrun-Frenay C, Cottalorda J, Biscay V, Ticchioni M, Dellamonica P, Neuradapt Study Group: LPS may be a predictive factor even in mild forms of HIV-associated neurocognitive impairment: sub-analysis of the neuradapt study. 18th Conference on Retroviruses and Opportunistic Infections, Boston MA 2011, Abstract 404.

32. Campbell JH, Burdo TH, Autissier P, Bombardier JP. Westmoreland SV, Soulas C, González RG, Ratai EM, Williams KC: Minocycline inhibition of monocyte activation correlates with neuronal protection in SIV neuroAIDS. PLoS One 2011, 6:e18688.

33. Buckner CM, Calderon TM, Willams DW, Belbin TJ, Berman JW: Characterization of monocyte maturation/differentiation that facilitates their transmigration across the blood-brain barrier and infection by HIV: implications for NeuroAIDS. Cell Immunol 2011, 267:109-123.

34. Chong WK, Paley M, Wilkinson ID, Hall-Craggs MA, Sweeney B, Harrison MJ, Miller RF, Kendall BE: Localized cerebral proton MR spectroscopy in HIV infection and AIDS. AJNR Am J Neuroradiol 1994, 15:21-25.

35. Chang L, Ernst T, Leonido-Yee M, Witt M, Speck O, Walot I, Miller EN: Highly active antiretroviral therapy reverses brain metabolite abnormalities in mild HIV dementia. Neurology 1999, 53:782-789.

\section{Pre-publication history}

The pre-publication history for this paper can be accessed here: http://www.biomedcentral.com/1741-7015/9/138/prepub

\section{doi:10.1186/1741-7015-9-138}

Cite this article as: Torti et al: Asymptomatic neurocognitive disorders in patients infected by HIV: fact or fiction? BMC Medicine 2011 9:138.

\section{Submit your next manuscript to BioMed Central and take full advantage of:}

- Convenient online submission

- Thorough peer review

- No space constraints or color figure charges

- Immediate publication on acceptance

- Inclusion in PubMed, CAS, Scopus and Google Scholar

- Research which is freely available for redistribution

Submit your manuscript at www.biomedcentral.com/submit
Ciomed Central 